\title{
Building a Conceptual Framework for E-Learning Based on Cloud Computing In Egyptian Universities
}

\author{
Christin Albert Rayed, Bayoumi Ahmed Bayoumi
}

Associate professor, Computer and information system department

Sadat academy for management science,

$$
\text { Cairo, Egypt }
$$

christinalbert2004@yahoo.com

System Administrator, Alenjaz Trading and contracting company,

$$
\text { Ryiadh - KSA }
$$

\section{baumey@outlook.com}

\begin{abstract}
In order to have an intelligent education, we have to make use of all modern education techniques. One of these techniques is the integration of information and communication technologies in education according to the global trend. In other words, to prepare a creative environment using means of existing web tools, techniques, and services to provide Browser-Based-Application. Nowadays Arab countries have a big interest in E-learning techniques and put it into the form of services within Services Oriented Architecture Technique (SOA), and mixing its input and outputs within the components of the Education Business Intelligence and enhance it to simulate reality by educational virtual worlds. This paper presents an idea about tools, instruments, techniques to enhance the educational process in the way that it could reach maximum uses of intelligent education modern technique.
\end{abstract}

\section{Indexing terms/Keywords}

Cloud computing, E-learning, E-education.

\section{Academic Discipline And Sub-Disciplines}

Computer Science; Education;

\section{SUBJECT CLASSIFICATION}

Cloud computing

\section{TYPE (METHOD/APPROACH)}

Practical Study

\section{INTRODUCTION}

In recent times, there have been advances in the development of social software technology in particular in the field of education. Blended learning strategies can optimize the integration of multi-modal, multi-channel and multi-source learning which includes online and traditional learning, this helps learners develop and improve their learning autonomy and to selfmanage to best suit their learning style, lifestyle and work style. Such software applications are generally developed on web 2.0 tools, for example m-learning applications, twitter, YouTube, slide share, Picasa, media wiki, etc. In the field of education this software is used to help teachers to monitor students' activities. In specific terms, e-learning is based not only on distributed learning, online learning, virtual learning, web based or networked learning but also on testing and evaluating the best feedback, intervention and the interaction of some platforms in e-learning environments between the instructor and learner. (Alowayr \& Badii, 2014)

When talking about Information and Communications Technology (ICT), should be increasingly talk about how ICT is supporting innovation, driving change and transforming the way of the work. (Cormann \& Turnbull, October 2014)

Cloud computing is a model for enabling ubiquitous, convenient, on-demand network access to a shared pool of configurable computing resources (e.g., networks, servers, storage, applications, and services) that can be rapidly provisioned and released with minimal management effort or service provider interaction. (Cormann \& Turnbull, October 2014)

\section{E LEARNING}

Electronic Learning (e-learning), is education based on modern methods of communication including the computer and its networks, various audio-visual materials, search engines, electronic libraries, and websites, whether accomplished in the classroom or at a distance. Generally speaking, this type of education is delivered through the medium of the World Wide Web (WWW) where the educational institution makes its programs and materials available on a special website in such a 
International Journal of Research in Education Methodology manner that students are able to make use of them and interact with them with ease through closed or shared, networks, or the Internet, and through use of e-mail and online discussion groups. A number of other terms are also used to describe this mode of teaching and learning. They include online learning virtual learning distributed learning network and webbased learning. Fundamentally, they all refer to educational processes that utilize information and communications technology to mediate asynchronous as well as synchronous learning and teaching activities. (Ajmera \& Dharamdasani, 2014)

\section{CLOUD COMPUTING PARADIGM}

Cloud computing is the latest trend in IT industry. Both industry and academia largely lack exact understanding and consensus of the nature and scope of this novel phenomenon. It is still unclear to define what cloud computing actually means and understanding how it affects the industry (Stanton, Theofanos , \& , December 2015 ). Cloud Computing is more detailed in the following subsections.

\section{CLOUD COMPUTING DEFINITION}

Cloud computing is the latest trend in IT industry. Both industry and academia largely lack exact understanding and consensus of the nature and scope of this novel phenomenon. It is still unclear to define what cloud computing actually means and understanding how it affects the industry (Stanton, Theofanos , \& , December 2015 ). Cloud Computing is more detailed in the following subsections.

the Cloud Computing definitions list, which is "A large-scale distributed computing paradigm that is driven by economies of scale, in which a pool of abstracted, virtualized, dynamically-scalable, managed computing power, storage, platforms, and services are delivered on demand to external customers over the Internet" (Al-Roomi, Al-Ebrahim, Buqrais, \& Ahmad, 2013).

According to (Al-Roomi, Al-Ebrahim, Buqrais, \& Ahmad, 2013), Cloud Computing is a specialized distributed computing paradigm which differs from traditional ones in that (1) it is massively scalable, (2) can be encapsulated as an abstract entity that delivers different levels of services to customers outside the Cloud, (3) it is driven by economies of scale, and (4) the services can be dynamically configured, via virtualization or other approaches, and delivered on demand.

\section{A CONCEPTUAL FRAMEWORK FOR DEVELOPING E-LEARNING BASED ON CLOUD COMPUTING}

The proposed framework is composed of a number of clearly defined and distinct layers, which are used by systems engineers and systems developers to plan for, design, build, test, and deliver information systems and to assure that developed e-learning cloud computing meet established requirements.

the conceptual framework for developing cloud computing e-learning systems. It discusses how Cloud Computing transforms the way e-learning systems are built/developed and describes the layers' considerations that developers must take when adopting and using Cloud Computing technology with e-learning systems. Finally, it shows how Cloud Computing technology can help the Higher Institute for Specific Studies e-learning System (HISS-ELS) in providing services to specific/interesting users. In order to test/experiment the proposed framework, there is a need to apply it on a real e-learning system that has real data and real situations. HISS is an educational institution for Management Information Systems (MIS) and Tourism Studies in Cairo, Egypt. As many institutions/universities turn their education systems to be on the internet, it is benefit to use cloud computing applications to customize, apply, test, and experiment the (HISS-ELS) to put it in practical use and to be tested as it finished.

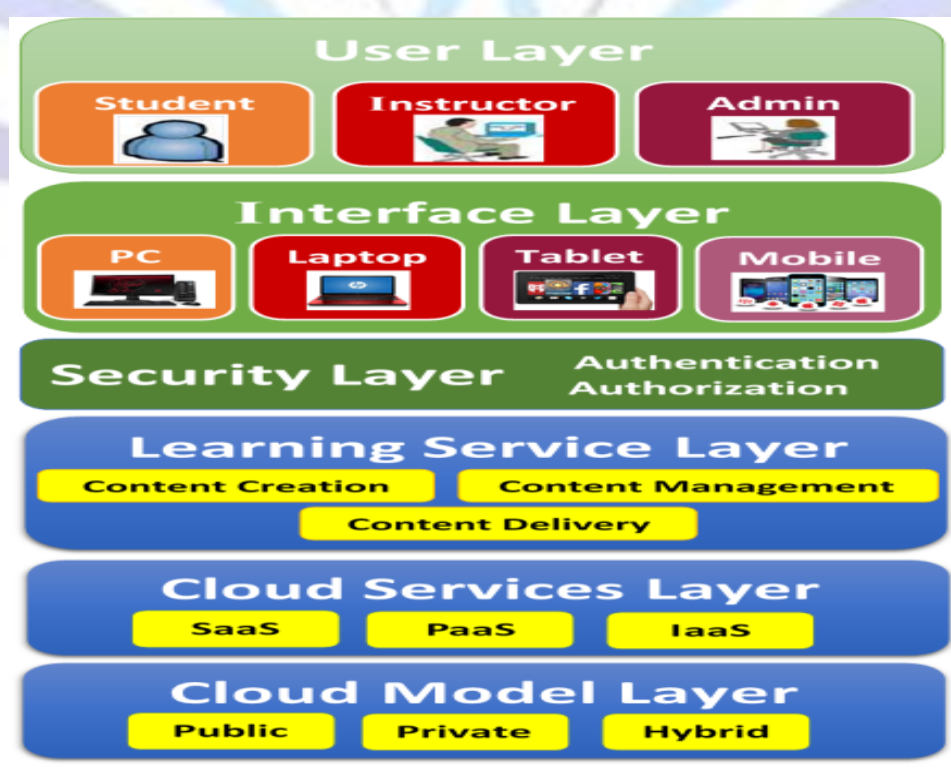

Figure 1: The Proposed Framework for E-Learning Based on Cloud Computing 


\section{The User Layer (UL)}

In this Layer, the system main users are determined. It contains all the system users which work with, use and/or maintain the underline educational system resources. Those users are: Students, Instructors, and the system Admins as shown in Figure 2.

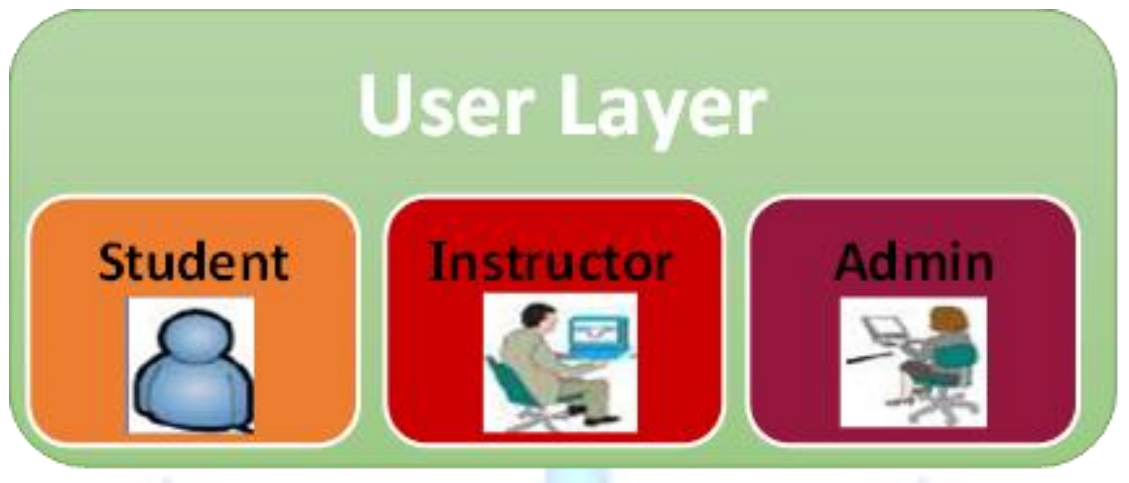

Figure 2: The User Layer (UL)

According to the HISS-ELS, users are divided into three roles, which are: (1) HISS Students, for whom the system is developed, (2) HISS Instructors, who provide courses' materials to their students, give assignments/exams, and assign grades, and (3) HISS Admins, who provide, manage, and maintain the main HISS data for both Students and Instructors.

\section{The Interface Layer (IL)}

This layer acts as an intermediate layer between the system users and its services. It connects the system users, defined in the User Layer (UL), with the Learning Services Layer (LSL). The connection is done by passing the Security Layer (SL) through any terminal which has an internet connection regardless to its hardware and/or installed operating system, Figure 3.

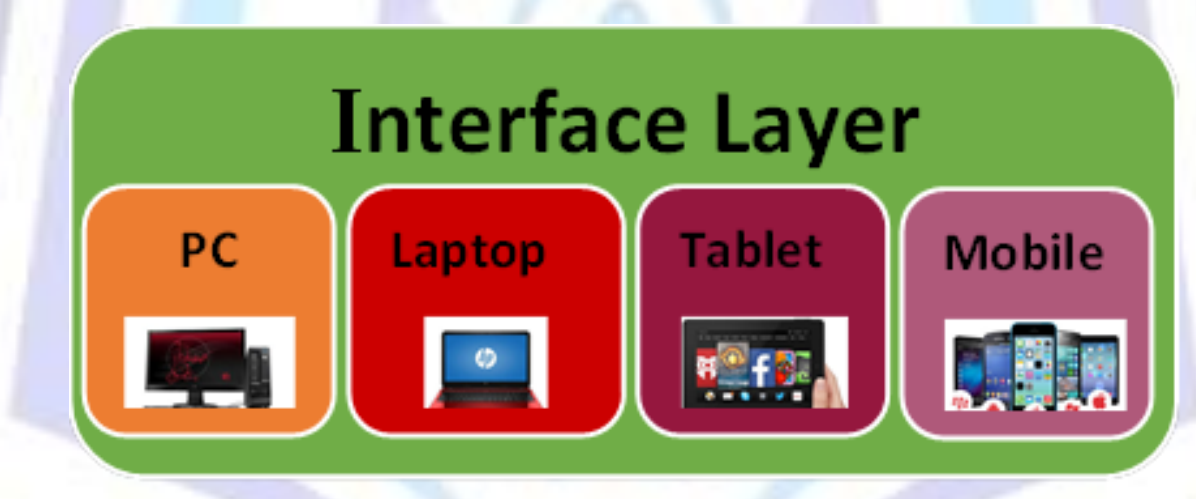

According to this layer, the HISS-ELS users can connect to their educational Cloud Computing System from anywhere any time by using any terminal that has an Internet connection. Those devices are such as, and not limited to: desktop PCs, Laptops, Tablets, PDAs, and/or Mobile devices.

\section{The Security Layer (SL)}

In order to use any system/application component, especially when clouds are used. The proposed framework adds this layer to secure e-learning cloud computing systems, Figure 4. In a simplest case, users must be first authenticated to secure the system services/components, then they can reach their authorized and related services.

\section{Security Layer Authentication \\ Authorization}

Figure 4: The Security Layer (SL).

The HISS-ELS requests its users to authenticate themselves by submitting their usernames and passwords. As users are authenticated after clicking on the Login button, they will access their subsystems and related modules, which are authorized to use. 
The Learning Services Layer (LSL)

This layer, as shown in Figure 5, contains three components that are necessary to be found in any traditional information system. The first component is the Content Creation (CCr), in which the basic data that is needed to the system to work is created. Content creation is mainly the responsibility of the system admins. The second one is Content Management (CM). This layer responsibility is to manage and maintain the system data to make the system survive for long time. The last layer is Content Delivery (CD), which is responsible of the interaction between the system and its users through the system feedback.

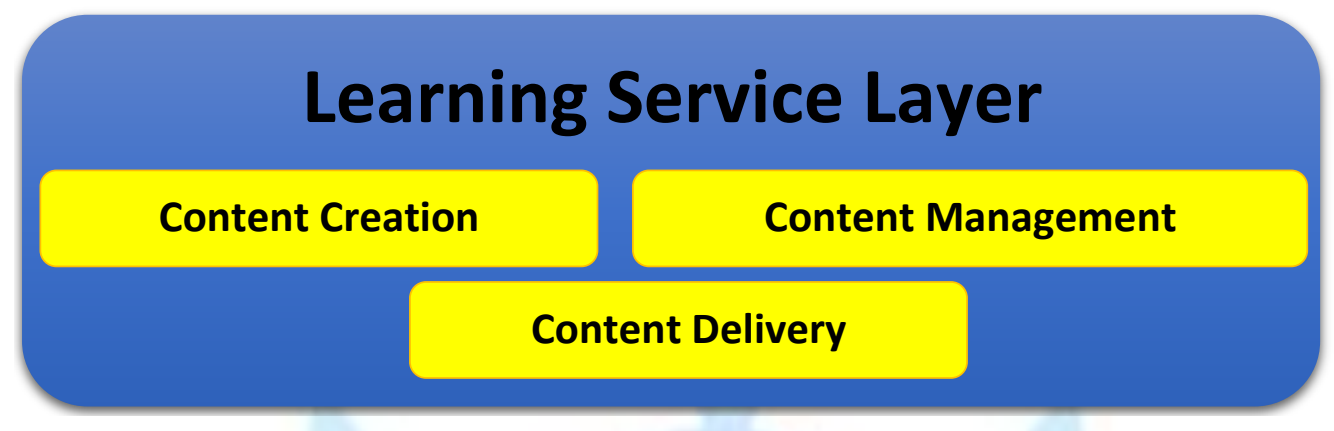

Figure 5: The Learning Service Layer (LSL)

The details of the Learning Service Layer components are shown in Figure 6.

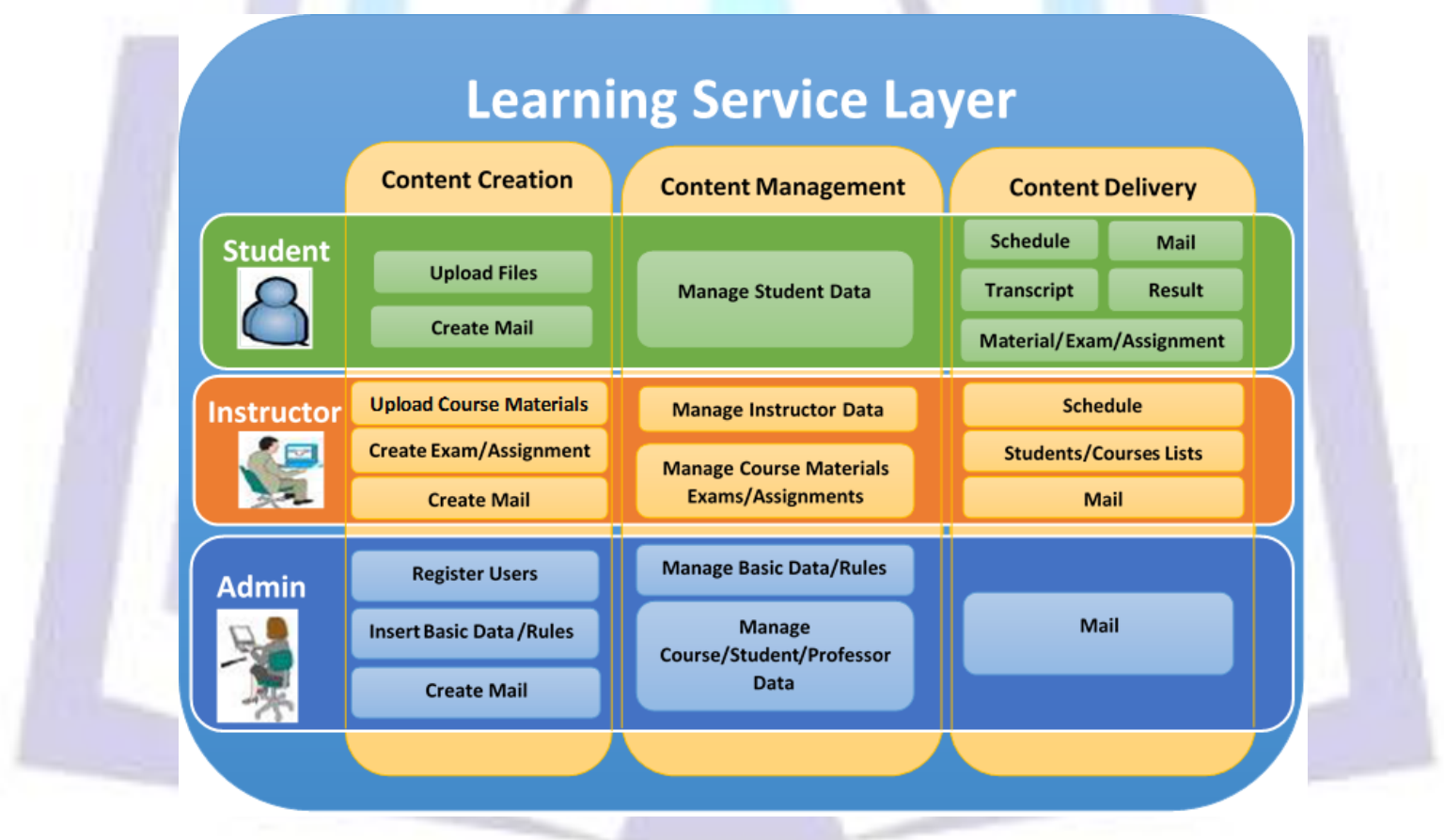

Figure 6: Details of the Learning Service Layer (LSL)

The proposed framework suggests some modules that supposed to be existed in any e-learning system. Those modules may be decreased or increased as needed.

\section{APPLYING PROPOSED CONCEPTUAL FRAMEWORK FOR E-LEARNING BASED ON CLOUD COMPUTING}

The implementation of HISS-ELS on the Force.com platform. It demonstrates the application implementation tools, scenario, rules and constraints, and the system GUI. Each subsystem implementation is illustrated in a separate section.

\section{Implementation phase}

\section{First: Hardware}

Any internet enabled device, PC, laptop, and/or Smart phone, with a thin client interface, such as a web browser. 
Second: Software

\section{Salesforce-Supported Tools}

\section{Developer Console}

A browser-based collection of tools that can be used to create, debug, and test applications.

\section{Force.com IDE}

Eclipse plugin for developing Force.com applications, providing source code editors, test execution tools, wizards, and integrated help.

\section{Force.com Migration Tool}

A Java/ANT-based command line utility for scripted deployment of application metadata.

\section{Community-Supported Tools}

\section{Force.com Explorer}

.NET-based tool for inspecting schema, and building and testing SOQL queries.

\section{HISS-ELS Scenario}

At the beginning of each semester, authenticated and authorized students request their courses' schedules for the current semester. Information about each course, such as professor, department, hours, location, and time are provided to help students. They can change some of their data, view/print their schedules/ transcripts, view/download courses' materials, manage their assignments and finally view take exams. Professors can view/print their schedules/course's students, manage courses' materials, make exams, and/or submit their students' grades. HISS-ELS has three main subsystems which are the students', professors', and the administrators' subsystem.

\section{The Main HISS-ELS Interface}

HISS-ELS all pages are consistent as it is based on a template which is designed by apex, visualforce, javascript and html on the force.com platform. The HISS-ELS site template is designed in three parts which are: (1) the site header that includes the main HISS-ELS banner and the main subsystem's links (2) the main page in which links' contents are displayed, and (3) the site footer which contains the HISS-ELS copyright

\section{The Student Subsystem}

This subsystem allows authenticated/authorized students to access their subsystems' modules to view/manage their details, view/print schedules/transcripts, view courses' materials, manage assignments, take exams and any other relevant information details.

\section{Professors Subsystem}

As professors authenticated/authorized to access their subsystems, they will access their main page.

\section{The Admin Subsystem}

This subsystem allows administrators to manage all HISS-ELS data such as data about professors, students, and/or courses, as soon as they are authenticated.

\section{Conclusion}

This paper provides a starting point for building a Conceptual Framework for Developing Cloud Computing E-Learning Systems to aid/support developers developing their e-learning systems easily with a systematic manner. The proposed framework composed of six clearly defined and distinct layers which are (1) User Layer (UL), which defines all the system main users who are use the underline educational system resources, (2) Interface Layer (IL), which acts as an intermediate layer between the system users and its services, (3) Security Layer (SL), which is used to secure the underline e-learning cloud computing system's resources, (4) Learning Service Layer (LSL), which includes three components to create, manage, and deliver content, (5) Cloud Service Layer (CSL), in this layer, the appropriate cloud service model is selected based on the system design, services and/or specifications, and finally, (6) Cloud Model Layer $(\mathrm{CML})$, in which the system deployment model is selected according to the system specification, partners, owners, and the needed security level.

In order to test and experiment the proposed framework, a new application, HISS-ELS, was built from scratch based on this proposed framework. HISS-ELS has been developed to implement important functions that aid to the better functioning of a E-Learning as a Service (ELaaS). It has to allow users to login to their authorized subsystems. Students are allowed to view/edit their details, get their schedules and/or courses' materials, manage their assignments/exams, get their scores and results. Instructors are allowed to provide courses' materials to their students, give assignments/exams, and assign grades. Finally, admins are allowed to provide, manage, and maintain the main HISS data for both Students and Instructors. 


\section{FUTURE WORK}

The proposed framework needs to be tested and experimented on more numbers of applications with different types, functionalities and plans; such as systems which work by the credit hours' plan, in order to investigate and determine its merits and limitations. It is also worth to test it against legacy applications as well as custom applications, in order to analyze the feedback with respect to applicability. Finally, the applied application needs to be customized and applied on.

\section{REFERENCES}

I. Alowayr, A., \& Badii, A. (June 2014). REVIEW OF MONITORING TOOLS FOR E-LEARNING PLATFORMS. International Journal of Computer Science \& Information Technology (IJCSIT), 79 - 86.

II. Cormann, M., \& Turnbull, M. (2014, OCTOBER). Australian Government Cloud Computing Policy Version 3.0. Australian Government Cloud Computing Policy Version 2.1 July 2013.

III. Ajmera, R., \& Dharamdasani, D. K. (2014). E-Learning Quality Criteria and Aspects. International Journal of Computer Trends and Technology (IJCTT).

IV. Stanton, B., Theofanos, M., \& , K. (December 2015 ). Framework for Cloud Usability. National Institute of Standards and Technology- NIST.

V. Al-Roomi, M., Al-Ebrahim, S., Buqrais, S., \& Ahmad, I. (2013). Cloud Computing Pricing Models: A Survey. International Journal of Grid and Distributed Computing, 93-106.

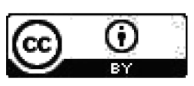

This work is licensed under a Creative Commons Attribution 4.0 International License.

DOI :10.24297/ijrem.v7i5.5159 